\title{
LA CRISIS DE LA DEMOCRACIA Y LOS NUEVOS ESCENARIOS QUE SE PLANTEAN
}

\author{
Pedro Ibarra \\ Universidad del País Vasco
}

RESUMEN: El texto reflexiona sobre la profundidad y extensión de la crisis democrática, tanto en los procesos de representación formal como en la desaparición de la autonomía real decisoria en las instituciones. Respondiendo a esta crisis, se desarrollan dos propuestas regenerativas. Una del mismo proceso representativo. Otra, considerando insuficiente la anterior, consistente en introducir otros espacios de democracia.

Palabras clave: democracia, participación, poder político.

RESUM: El text reflexiona sobre la profunditat i extensió de la crisi democràtica, tant en els processos de representació formal com en la desaparició de l'autonomia real decisòria en les institucions. Responent a aquesta crisi, es desenvolupen dues propostes regeneratives. Una del mateix procés representatiu. Una altra, considerant insuficient l'anterior, consistent a introduir altres espais de democràcia.

PARAUles Clau: democràcia, participació, poder polític.

ABSTRACT: The paper reflects on the breadth and depth of the crisis of democracy both in the processes of formal representation and in the disappearance real decision-making autonomy in institutions. Two proposals for 
regeneration are presented in response to this crisis; one is a proposal for the representative process; the second, considering the first to be insufficient, consists of introducing other democratic spaces.

KEYWORDS: democracy, participation, political power.

\section{Pero ¿qué es la democracia?}

$\mathrm{M}$ e temo que resulta inevitable hablar de qué es la democracia para luego poder hablar de si existe o no una crisis de la democracia. Pero el problema se complica porque no resulta nada claro establecer con qué criterios hacemos una definición de la democracia. El asunto tiene difícil salida, porque si establecemos una definición democrática minimalista en la cual tal régimen político sólo se caracteriza por tener de vez en cuando algún proceso electoral, indudablemente no estamos en una situación de crisis. Si por otro lado, en el otro extremo, caracterizamos una democracia como un régimen político en el cual los ciudadanos - todos los ciudadanos - toman directamente sin mediación todas las decisiones que afectan al interés general, tampoco estamos en crisis. La crisis supone cambio (aceptemos que a peor) respecto a una situación anterior y una situación anterior como acabamos de escribir nunca ha existido. La opción realista y la utópica nos conducen a un callejón sin salida. La única salida es construir una definición. Describir una serie de procesos, circunstancias y elementos centrales que configuran dinámicamente una adecuada democracia. Pero, ¿qué quiere decir adecuado? ¿Adecuado para qué y para quién?

Podríamos dedicar un montón de páginas a describir las distintas teorías y afirmaciones retóricas que hay sobre lo que debe ser la democracia. ${ }^{1}$ Parece,

1. Las referencias bibliográficas que siguen son una sucinta muestra de clásicos y autores más actuales sobre el debate democrático: Dahl, (1998); Held, (2006); Diamond, (1999); Manin, (1997); Morlino, (1998); Przeworski, (1998);Putman, (2002); Sartori, (1987); Schmitter y Kart, (1991) y Stokes, (2002). 
sin embargo, más operativo hacer una reflexión a partir de lo que los ciudadanos de izquierdas entienden o intuyen como democracia verdadera. Veremos. En todo caso haré alguna puntualización sobre algunas de las teorías actuales más conocidas. En el campo realista/minimalista/autoritario destaca la (por otro lado interesada) majadería de identificar la democracia con la ley. Nos dicen que nada hay tan democrático como cumplir la ley. Les decimos que no hay nada tan democrático como desobedecer la ley. Los ciudadanos rechazan la ley porque y para que políticos hagan otra ley de acuerdo con lo quieren esos ciudadanos. El impacto ciudadano en el quehacer $-\mathrm{y}$ los contenidospolíticos cotidianos es... la democracia.

Desde el otro lado, donde la hemos calificado como enfoque utópico, aparecen distintas teorías. Democracia participativa, democracia asamblearia, democracia deliberativa, democracia asociativa, etc. ${ }^{2}$ En el fondo, todas ellas proponen fórmulas a través de las cuales existe una participación ciudadana real en las decisiones políticas. Mi reflexión, sin duda, parte de estas propuestas pero creo que las mismas, o parte de las mismas, hay que encajarlas en un proceso dinámico que además tiene otros frentes transformadores. ${ }^{3}$

Para empezar, vamos a reflexionar solo sobre democracia política. Sobre el cómo y el porqué las decisiones políticas, aquellas decisiones que se toman por las distintas instituciones políticas y que por tanto hacen referencia al $-\mathrm{O}$ a un- interés general, son democráticas (o no). Sin duda, las relaciones y dependencias entre democracia política y la democracia de y dentro de otras instituciones y organizaciones sociales, y entre ellas especialmente las económicas, son evidentes y las veremos también lo largo de esta reflexión. Pero para arrancar el proceso analítico, vamos a fijarnos exclusivamente ahora en la democracia política.

2. Las referencias que siguen son muestra de las actuales reflexiones sobre las otras democracias - participativa, deliberativa, etc.-: Bacque y Sintomer, (2005); Baker, (2002); Cohen, (1998); Dryzek, (2000); Khane, (2002); Stokes y Carter (2002); Mansbridge et al. (2010); Nino, (1996); Pettit, (1999); Shapiro y Hacker-Gordon (1987); Sintomer, (2007); Sousa Santos, (2002); Teorell, (2006); Warren, (2001); Zolo, (1992).

3. Mi orientación analítica sobre la democracia se apoya en lo que podríamos denominar genéricamente como teorías del proceso democrático o democratización. En esta opción algunos de los autores más relevantes son los que siguen: Laclau, (1996); Mouffe, (1993); Tilly, (2007, 2003); Welzel, (2013). Para un punto de vista analítico sobre estas teorías, ver mi libro Democracia relacional, 2011, CEPC, Madrid. 


\section{A. En el terreno de lo posible alternativo}

Si resulta imposible una coincidencia formal y total, sistemática y permanente, entre, por un lado, todos los deseos, intereses e identidades de lo ciudadanos y, por otro, todas las decisiones políticas que deben tomarse, deberemos buscar esa coincidencia en los hechos. Es decir, admitiendo como inevitable una determinada representación política (aunque esta representación no debe darse siempre y en todos los espacios), el proceso democrático - la democracia adecuada - tendrá que basarse más en realidades de convergencia.

\section{B. En el terreno de la definición}

Una definición de apertura. Ciudadanos iguales con los mismos derechos democráticos (libertad expresión, reunión, etc.), con la mismas capacidades de ejercerlos ${ }^{4}$ y la misma capacidad de influir en los asuntos públicos. Todo lo que hacen todos los ciudadanos en todos sus ejercicios democráticos — desde votar a manifestarse contundentemente exigiendo decisiones políticas radicalmente distintas - a favor de que lo que ellos quieren que se halle presente en las decisiones políticas de las instituciones tiene el mismo impacto en el proceso político decisorio formal.

\section{En el terreno del supuesto sentido común}

Finalmente, parecería que ésta es la creencia o intuición o propuesta, si no de todos los ciudadanos sí al menos la que se sitúa o proviene de la cultura o tradición de la izquierda. La idea de que somos nosotros los que mandamos y ellos - los representantes, los políticos - tienen que hacer lo que nosotros queremos. Ellos son sólo nuestros representantes y, por tanto, lo que tienen que hacer es saber qué es lo que queremos y decidir en consecuencia. Es la idea de que la democracia esta potencialmente en el pueblo, en un pueblo en el que no deben existir intereses privilegiados. Un pueblo que decide en última instancia. Esta convicción no se expresa evidentemente con el for-

4. Capacidad quiere decir poder querer ejercer y... ejercer. O sea, que los millones de ciudadanos que viven bajo el umbral de pobreza no es que no tengan menos capacidad que otros, es que no tienen capacidad. 
mato y lenguaje de mi formulación antedicha. Por otro lado, y esto conviene remarcarlo, la misma no se corresponde necesariamente con la puesta en marcha del ejercicio de los diversos derechos y capacidades en diversos frentes y espacios. En concreto, una cosa es tener esa convicción democrática y otra cosa es su práctica: la cultura democrática. La carencia de cultura democrática en ocasiones desvirtúa la propia convicción democrática, derivando la misma hacia una posición puramente pragmática. A una posición de estricta pasividad en la que se asume el discurso dominante. Aquél que dice - que nos dice - que en realidad lo que nosotros queremos es que alguien - los políticos - nos resuelvan los asuntos comunes. Y que esos mismos, a los que sólo pedimos que no roben demasiado, nos dejen en paz para poder gestionar tranquilamente nuestros asuntos privados.

Hay democracia cuando todos los ciudadanos están presentes en el proceso de decisión política, cuando los ciudadanos no se sienten excluidos porque realmente no están excluidos de ese proceso de decisión política. Por tanto, para seguir avanzando, lo que tenemos que hacer es desarrollar esa relación de presencia y exclusión en el proceso decisorio, y avanzar desde la exclusión a la máxima presencia.

El punto de salida en ese avance es la representación. Los representantes políticos elegidos, en cuanto que nos representan, se supone que tienen presente en sus decisiones los intereses de sus representados. Por tanto, si esos representantes son libremente elegidos, si nos representan aquellos que queremos que nos representen y si, por otro lado, ejercen su representación de forma digna y honesta, podemos decir que como hay presencia, y ésa se reconoce por los representantes, hay democracia. Hay adecuada democracia. Pues no. Esto sólo es el comienzo. El punto de partida.

Ahora conviene recordar la realidad. Recordar que la historia de la democracia es la historia de la lucha por la democracia. De cómo cada vez mayores grupos de la sociedad lucharon para conseguir estar ellos también en el poder, en las decisiones políticas.

En el origen, la identificación entre poder económico y poder político era absoluta. Eran los mismos. Más tarde, en los orígenes de la democracia, son sólo los detentadores del poder económico los que eligen a los políticos. Luego, a través de un permanente y no siempre victorioso proceso de lucha, toda 
la sociedad progresivamente (clase medias, trabajadores, mujeres) se incorpora a ese proceso electoral. Se puede afirmar que desde el estricto punto de vista formal del proceso representativo, todos los ciudadanos están presentes en la voluntad política de sus representantes. Desde la perspectiva formal. Porque, realmente, el peso de las élites económicas y determinados grupos de poder de hecho están mucho más presentes que el resto de los ciudadanos en ese proceso. Antes, políticos y poderes reales eran los mismos, ahora, los políticos son sus representantes. Ahora, la lucha por la democracia va dirigida a la inclusión de todos los ciudadanos en los espacios y procesos en donde se toman realmente las decisiones políticas.

\section{La crisis}

Teniendo como punto de partida y también como enmarque la propuesta de la democracia adecuada vamos a ver en qué consiste este asunto de la crisis. Algunas hipótesis:

1. Si realmente existe una crisis. Si lo que está ocurriendo pone en cuestión los cimientos de la democracia y por tanto exige inevitablemente reconstruir, o construir, una democracia basada en otros parámetros.

2. Si las democracias realmente existentes - la democracia representativa en su sentido más estricto- es la que está en crisis o, por el contrario, lo que está en crisis es lo que creemos que debería ser esa democracia representativa (la adecuada).

Sin duda, la democracia está siendo afectada por el proceso de globalización, especialmente en su dimensión económica y muy especialmente en los recientes y dramáticos años de la crisis económica. Esta situación presenta en toda su radicalidad una de las insuficiencias constitutivas de la representación democrática, la falta de autonomía de los representantes políticos.

\section{A. La autonomía}

El proceso de toma de decisiones en una democracia representativa se inserta en lo que se puede denominar dos espacios de influencia decisoria. El formal y el real. El primer espacio es el formal, el convencional, es el 
conformado a través del proceso electoral. A través del mismo, los representantes - los gobernantes - se supone que toman decisiones dirigidas a buscar el interés general en virtud de que el conjunto, o los amplios conjuntos de la población a quien representan, expresan y simbolizan ese interés general. Se supone. Porque es evidente que el mecanismo de representación en el que se basa la democracia representativa en modo alguno implica un mandato imperativo. En modo alguno los representantes están sometidos a las específicas directrices o exigencias formuladas por los representados. La representación otorgada implica la más absoluta y total delegación. Los representantes pueden hacer lo que les venga en gana. No tienen por qué conocer ni saber a través de sus representados en qué consiste ese interés general. Es más, como su mandato no se lo exige, no establecen relación alguna con sus representados para conocer qué es lo que realmente quieren que se haga.

En la democracia representativa, por definición, no existe comunicación entre representantes y representados. Por definición, quiere decir que los representantes «que pasan» de sus representados y hacen lo que les viene en gana, no es porque sean especialmente perversos, sino porque eso es lo que establece el sistema democrático representativo.

En consecuencia, en este espacio de influencia decisoria... no hay influencia. Los representantes están solos porque quieren estar solos y porque deben estar solos de acuerdo con los parámetros establecidos por la democracia representativa. Los representantes están desnudos a la hora de tomar decisiones políticas.

\section{B. La desaparición de la autonomía}

La frase anterior es literatura, porque esos representantes toman decisiones dentro de lo que llamaremos el espacio de influencia real. La cuestión es muy conocida. Grupos organizados presionan a esos representantes para que tomen decisiones a favor de sus intereses grupales, que por supuesto nada tienen que ver con el interés general.

Se hallan desnudos y al mismo tiempo son extremadamente receptivos a ser vestidos por esos concretos grupos de presión. Es evidente de quién estoy hablando: mercados, banca, multinacionales, etc. Pero no es tan evidente el 
mecanismo, el proceso de presión y el correspondiente resultado en la decisión política. Un par de pistas. Los resultados se logran, esto es, los políticos toman las decisiones que quieren esos grupos, por su capacidad de chantaje. Es decir, por su capacidad de amenazar con medidas perjudiciales, con específicos daños, dirigidos tanto a los mismos políticos como a la sociedad que algunos de esos políticos creen que deben proteger. Retengamos este dato: a más daños previsibles mejores resultados de la presión ejercida.

Pero hay también otra razón, una segunda pista para acercarnos a este proceso. La que constata que esos políticos coinciden plenamente con el modelo de sociedad de desigualdad, de jerarquía y de darwinismo social propuesto por esos grupos. Dicho de otra forma, no se sienten amenazados. Hay una absoluta correspondencia entre los deseos y exigencias de esos grupos y las políticas que ya de antemano quieren hacer esos satisfactoriamente presionados políticos.

Los políticos, con su política de reajustes, desmantelamiento y desprotección del bienestar social y en última instancia de la igualdad, coinciden plenamente con los grupos de presión económico. Ambos entienden que el poder está en el mercado, y dentro del mercado, en aquellos que ocupan posiciones de privilegio y poder. Que ello genere desigualdad es un problema que no les preocupa lo más mínimo. Si el interés general no coincide con los determinados intereses privados, peor para el interés general.

La cuestión de la autonomía se plantea en este proceso. Volviendo al escenario anterior, se podía afirmar que esa absoluta desvinculación, no dependencia y soledad de los representantes frente a sus representados, sus electores, les otorgaba una situación de plena autonomía. Sólo ellos sin ninguna influencia ni mandato ni control ni exigencia exterior, decidían lo más conveniente. El problema es que obviamente los hechos, las influencias, presiones reales, destruyen, también de hecho, esa autonomía. La genérica independencia es sustituida por una concreta dependencia y coincidencia.

\section{De la indiferencia al desprecio}

Se puede por tanto considerar que hay un serio desajuste en el regular funcionamiento de la democracia representativa. La no dependencia de los 
representantes respecto de sus representados ha derivado hacia un proceso de desprecio objetivo. Si esa no dependencia constitutiva del proceso de representación podía antes generar una genérica actitud de indiferencia frente a los ciudadanos, la ahora sustancial dependencia respecto a determinados grupos de presión, la destrucción de su estatus de autonomía, provoca una toma de partido. Genera una actitud proactiva, casi hostil, frente al interés general representado por el conjunto de los representantes. Y, por tanto, una actitud de desprecio (evidentemente nunca verbalizado) respecto a sus representados. Éste es el panorama.

Algunas de las limitaciones y contrapesos internos, que en cierto modo moderaban las tendencias despóticas de los regímenes democráticos, parecen estar desapareciendo.

\section{Otra política democrática}

Frente a ello, parece necesario plantearse un conjunto de medidas dirigidas a la regeneración democrática. Pero debemos prestar atención a esta propuesta regenerativa. Y ello es así porque dependiendo de cómo veamos a la democracia deberán formularse unas u otras medidas.

1. Si entendemos que esta, llamémosla así, «crisis de la autonomía» obedece a una situación coyuntural, hay que proponer medidas que, por un lado, generen algunas dinámicas de influencia y comunicación en el espacio convencional, y otras, por otro lado, que logren un mayor equilibrio en el espacio de influencias real. Esta opción conlleva, aunque sea implícitamente, la creencia de que el modelo de la democracia representativa es no sólo el más deseable sino también el único posible.

2. La segunda opción parte de afirmar que esta actual cuasi desaparición - desaparición deseada como vimos - de la autonomía no es mera coyuntura, es ya constitutiva de la actual democracia representativa. Por tanto, la regeneración de la misma implica tomar medidas que hagan imposible un desequilibrio en la presión destinado a la desaparición de la autonomía. Hace necesario, por tanto, además de otra serie de medidas que se indicarán, la presencia operativa del 
interés general, a través de la participación ciudadana, en el proceso de toma de decisiones. Dicho de otra forma: no es tanto cuestión de buscar mejores equilibrios en las influencias, sino más bien de impedir las influencias de las minorías poderosas a través de la presencia de las mayorías sociales en el proceso decisorio. Es evidente que en dicha concepción está presente no sólo una opción táctica, orientada a no admitir una crisis coyuntural, sino una opción estratégica de fondo, aquélla que defiende otra democracia. Una democracia en la que, como se verá, las decisiones que cotidianamente y en diferentes espacios y formatos tomen los ciudadanos estén operativamente presentes en las decisiones que tomen los representantes políticos.

\section{Escenario y respuestas coyunturales}

Reflexiono ahora nuevamente sobre la crisis de la democracia desde la perspectiva más coyuntural, en la que se opera casi exclusivamente con el concepto de democracia representativa. La cuestión no es constitutiva sino de grado. Para ello, previamente precisaré algo más el enfoque convencional de la democracia representativa, en qué consiste realmente y no idealmente.

Existe democracia cuando las decisiones políticas son libremente y autónomamente tomadas por la mayoría de los representantes de los ciudadanos, libre, competitiva y limpiamente elegidos por esos mismos ciudadanos. $\mathrm{Y}$ existe democracia cuando todos los ciudadanos pueden ejercer en libertad un conjunto de derechos entre los cuales se hallan precisamente los dirigidos a hacer más libre y más cercana la elección de los representantes y su relación con los mismos; así, por ejemplo, la libertad de formar partidos políticos, de exigir publica y colectivamente el cambio (o mantenimiento) de determinadas políticas, etc.

Con esta propuesta, y teniendo también en cuenta lo que decía al principio, se puede establecer un primer escenario de crisis de la democracia. El que hace referencia a un sustancial aumento de los males de la representatividad. Los políticos representan cada vez peor los intereses de los ciudadanos, el interés común. A continuación un catálogo —absolutamente inconcluso- de 
estos males, de estos problemas ligados a una cada vez más miserable representación:

- Privilegios y perpetuidades en los cargos que los alejan de los ciudadanos.

- Mayor dependencia decisoria de minorías económicas.

- Falta de transparencia de sus decisiones.

- Corrupción.

- No poder decidir a quiénes queremos elegir. Ellos, los políticos, deciden a quiénes, de entre ellos y sólo de entre ellos podemos elegir.

- Desiguales e injustas representaciones, dependiendo de territorios y partidos.

Como puede observarse, la situación descrita define un escenario de empeoramiento. Una situación, que se estima como coyuntural, en la que los representantes, por un lado, han perdido autonomía, y por otro, se han distanciado más todavía de la voluntad de los ciudadanos. Sus sistemas de representación son arbitrarios, excluyentes. Están decididamente volcados a la búsqueda del interés propio, ignoran la crítica social, etc.

Conviene, en todo caso, recordar que estas insuficiencias no siempre son una degeneración del sistema. Son constitutivas del mismo. Lo que ocurre es que en la actual coyuntura aparecen sus efectos más negativos y más intolerables. El recordatorio no es obvio porque las medidas regenerativas que deberán proponerse no afectarán a alguno de los rasgos fundamentales y fundacionales de la democracia representativa; así, en concreto al carácter innegociable de la dimensión delegativa de la representación. Es decir, la imposibilidad de mediar eficazmente desde la sociedad en las decisiones políticas. Determinadas medidas harán que los políticos escuchen - con más o menos interés - lo que les digan los ciudadanos, pero en modo alguno esas medidas impedirán que, en última instancia, sigan decidiendo lo que les venga en gana.

En esta línea, las medidas regenerativas a proponer estarían dirigidas a:

A. Mejorar la representación convencional, generar algo más de influencia en el espacio convencional. Así, por ejemplo: 
- Cambios en los sistemas electorales. Lograr que los representantes sean más representativos.

- Cambios internos democráticos en los partidos. Lograr que los nominados para ser representantes sean más representativos.

- Cambios en privilegios y perpetuidades. Acercar más las condiciones de vida y trabajo de los representantes a los representados.

- Leyes de transparencia en la gestión política y económica a fin de evitar la corrupción.

- Establecimiento de rendiciones regulares de cuentas. Y establecimiento de mecanismos para la exigencia social de explicaciones públicas.

B. Pero también debería mejorarse el espacio de influencia real, tratar de lograr algo más de equilibrio en la autonomía. Para ello hay medidas que sólo dependen de nosotros. Ni de las leyes, ni de los políticos:

- Me refiero (como era previsible) a prácticas sociales - a la movilización social - en las que se acerca la voluntad de los ciudadanos a las decisiones de los políticos. Hablo de una sociedad civil activa en la que sus ciudadanos se movilizan en la calle, participan en espacios públicos decisorios, manifiestan su opinión a través de los medios, etc. Cuantos más ciudadanos con más frecuencia utilicen esos u otros cauces, en los que se expresen sus deseos, sus intereses, sus identidades, más probabilidades hay de que las concretas decisiones de los políticos asuman las demandas de los ciudadanos.

Tendremos así un mayor equilibrio en el espacio decisorio real. Tendremos así una democracia de más densidad, más democrática, en cuanto que existirá más coincidencia entre lo que los ciudadanos quieren que se haga y lo que los políticos hacen. Más coincidencia porque más y diferentes voces (un horizonte ideal sería el de todas las voces en situación de 
pleno equilibrio) confluyen con similar fuerza y capacidad de presión en los distintos espacios y procesos decisorios.

- También me refiero a grupos de ciudadanos que de forma estable, organizada y regular, deliberan y toman decisiones sobre asuntos que afectan al bien común. Esas decisiones, en principio no vinculantes para las instituciones políticas decisorias, son, sin embargo, tenidas en cuenta por los gobernantes. Estoy señalando a algunas de las actuales y diversas experiencias y procedimientos de la (mal llamada) democracia participativa. Desde comisiones sectoriales que operan en los Ayuntamientos a consultas precedidas en algunos casos por procesos más o menos asamblearios.

\section{Escenario y respuestas sistémicas}

La segunda situación describía esta deriva hacia el deterioro democrático como algo consustancial al modelo. Un determinado sistema económico antes generaba un desequilibrio en la autonomía decisoria. Pero un nuevo sistema —el actual - genera la desaparición del desequilibrio. La dependencia — además deseada - de los representantes es ya hoy sólo de uno. Y por lo que parece, el sistema que genera este monopolio tiene aspecto de ser muy duradero.

Esta caracterización haría bastante ilusoria no sólo la regeneración en el espacio convencional de la representación, sino también el intento de buscar un mayor equilibro en el proceso real decisorio. Por tanto, esta otra estrategia sistémica deberá cuestionar el mismo principio de representación. Tratará de impedir que los representantes tomen por sí solos las decisiones. Pretenderá, no tanto influirles, sino sustituirles o, al menos, introducir real y formalmente las decisiones y exigencias ciudadanas en sus decisiones políticas.

Es el momento de hacer una breve afirmación proveniente de la democracia participativa y decir que la democracia está en crisis, porque no existe democracia participativa o participación ciudadana decisoria; decir que la democracia está mal porque las decisiones políticas no las toman los ciuda- 
danos - ésa es la verdadera democracia—, sino los representantes políticos. La critica, ahora pues, se dirige al principio de representación y a su práctica.

Con este panorama sistémico y su correspondiente exigencia, alentada además por la filosofía de la democracia participativa, muy sucintamente apunto algunas propuestas posibles para lograr otra democracia.

- En primer lugar, se trataría de radicalizar las propuestas antes indicadas para regenerar la democracia representativa. Efectivamente, si por el momento no parece posible un modelo de sustitución de la representación, sino tan sólo avanzar hacia un control e incidencia operativa popular de la representación, se acelera y extiende ese control en cuanto que crece y se hacen más exigentes las prescripciones y prácticas antes descritas de transparencia, de rendición de cuentas, de democracia interna partidaria, etc.

- En segundo termino, qué duda cabe que un incremento sustancial de la movilización social no sólo facilitaría sino que también compartiría la presencia eficaz de la voluntad popular en los procesos decisorios.

- Y por último, pero sobre todo, me refiero a que esas deliberaciones y decisiones ciudadanas que antes describíamos como no vinculantes, ahora sean... vinculantes. Esto es la democracia participativa. Un cambio del sujeto decisorio. En este sentido viene a cuento decir que las experiencias participativas que antes detallaba no son prácticas de transformación de la democracia representativa hacia una más participativa. En su mayoría, las experiencias de participación ciudadana hoy existentes son, sobre todo, estrategias institucionales dirigidas a desviar la atención ciudadana sobre la crisis de la democracia representativa.

- Finalmente, hay que considerar el equilibrio en el espacio de influencia decisoria real. Sin duda, la presencia de más actores colectivos de carácter social en ese espacio, provenientes de la movilización social o bien de grupos de participación ciudadana, reequilibrará la influencia. No sólo los grupos de presión económicos serán los únicos socios privilegiados de los gobiernos a la hora de tomar decisiones; eso es 
cierto, pero también lo es que la capacidad de presión de esos grupos es siempre superior a los otros. Esos grupos representan aspectos estratégicos centrales a la hora de definir y establecer el interés general. Las políticas centrales - financieras, laborales, etc.- están en manos privadas. Así, las orientarán - las orientan - en favor de sus intereses particulares y lo harán con una capacidad de presión superior. En consecuencia, el equilibrio no sólo tendría que restablecerse a través de un aumento sustancial de actores en ese espacio decisorio, sino que además esos grupos de especial poder tendrían que actuar en la búsqueda del interés general, para lo cual, inevitablemente, deberían formar parte del sector público.

\section{Hacia dónde}

Sin duda parece más deseable operar a partir del segundo escenario y poner así en marcha espacios de contrapoder real. Pero no conviene olvidar dos cosas:

Una. Que la actitud dominante - muy dominante — de la sociedad frente a la crisis democrática es la de reconocer la deriva de la misma y la necesidad de su regeneración. De regeneración de la democracia representativa. No de sustitución de la representación.

Otra. Que a lo mejor debería considerase también (¿o en vez de?) una estrategia de salida. No sería cuestión de presionar, o de oponerse, o de intentar cambiar el poder, sino en pensar cómo salirse del sistema y empezar a decidir —en todo - al margen de él. Pero bueno, esto es... otra historia.

\section{Referencias}

Bacque, M. H. ; H. Rey y Y. Sintomer (2005): Gestión de proximitè y democratie participative, La Decouverte, Paris.

Baker, G. (2002): Civil Society and Democratic Theory. Alternative Voices, Routledge, London.

Cohen, J. (1998): «Democracy and Liberty». In Elster, J. (ed.): Deliberative Democracy. Cambridge University Press, Cambridge. 
DAHL, R. (1998): On Democracy. Yale University Press: New Heaven, Connecticut.

Diamond, L. (1999): Developing Democracy, The Jhon Hopkins University Press, Baltimore

DryzeK J. S. (2000): Deliberative Democracy and Beyond, Oxford University Press, Oxford.

Held, D. (2006): Models of Democracy. Polity Press: Cambridge.

Khane J. (2002): «Democracy and Group Rights». In Stokes G. and A. CarTER (eds.): Democracy Theory Today, Polity, Cambridge.

LAClAU, E. (1996): Emancipation(s), Verso, London.

Manin, B. (1997): The Principles of Representative Government. Cambridge University Press, Cambridge.

Mansbridge, J. ET AL. (2010): «The Place of Self-Interest and the Role of Power in Deliberative Democracy», en The Journal of Political Philosophy, Vol. 18, no 1, pp. 64-100.

McAdam, D.; S. Tarrow y Ch. Tilly (2001): Dynamics of contention, Cambridge University Press, Cambridge.

Morlino, L. (1998): Democracy Between Consolidation and Crisis. Oxford University Press, Oxford.

Mouffe, Сн. (1993): The return of the political, Verso, London.

Nino C. S. (1996): The constitution of deliberative democracy, Yale University Press, New Haven.

Pettit Рн. (1999): «Republican Freedom and Contestatory Democracy». In Shapiro I. and C. Hacker-Gordon (eds.): Democracy's Value. Cambridge University Press, Cambridge.

Przeworski, A. (1998): «Deliberation and Ideological Domination». En ElsTER, J. (ed.): Deliberative Democracy . Cambridge University Press, Cambridge.

Putman, R. (2002): Democracies in Flux. Oxford University Press, Oxford.

SARToRI, G. (1987): The Theory of Democracy Revisited, Chatham House Publishers, Chatham, New Jersey.

Schmitter Ph. C. y Kart T. L. (1991): «What democracy is... and is not», Journal of Democracy 3, p. 3.

Sintomer, Y. (2007): Le pouvoir au people, La Decouverte, Paris.

Sousa Santos, B. (coord.) (2002): Democratizar la democracia, fCe, México. 
Stokes G. (2002): «Democracy and Citizenship». In Stokes G. and A. CarTER (eds.): Democracy Theory Today, Polity, Cambridge.

Teorell J. (2006): «Political Participation and Three Theories of Democracy: A Research Inventory and Agenda». European Journal of Political Research, Vol. 45, p. 787.

Tilly, Сн. (2007): Democracy, Cambridge University Press, Cambridge.

- (2003): «When Do (and Don't) Social Movements Promote Democratization?». En Ibarra, P. (ed.): Democracy and Social Movements, Palgrave, New York.

Warren, M. (2001): Democracy and Association, Princeton University Press, Princeton.

Welzel, C. (2013): Freedom Rising, Cambridge University Press, Cambridge.

Zolo, D. (1992): Il principato democratico: per una teoria realistica della democrazia, Feltrinelli, Milano. 
